\title{
Exploration Life Support Technology Development for Lunar Missions
}

\author{
Michael K. Ewert and Daniel J. Barta \\ NASA Johnson Space Center, Houston, Texas, USA \\ Jeff McQuillan \\ MEI Technologies, Inc., Houston, Texas, USA
}

\begin{abstract}
Exploration Life Support (ELS) is one of the National Aeronautics and Space Administration's (NASA) technology development projects managed by NASA's Exploration Technology Development Program (ETDP), under the guidance of the Advanced Capabilities Division of the NASA's Exploration Systems Mission Directorate (ESMD). ELS plans, coordinates and implements the development of new life support technologies for human space exploration. ELS content includes four functional elements: Atmosphere Revitalization Systems (ARS), Water Recovery Systems (WRS), Waste Management Systems (WMS) and Habitation Engineering, and two cross cutting elements, Systems Integration, Modeling and Analysis (SIMA), and Validation and Testing.
\end{abstract}

The ELS project utilizes in-house efforts at five NASA centers. ELS is managed from Johnson Space Center and includes Marshall Spaceflight Center, Kennedy Space Center, Ames Research Center and Glenn Research Center [3]. The ELS project also incorporates aerospace industry contracts, university grants, Small Business Innovative Research (SBIR) contracts and other means to develop advanced life support technologies. Testing, analysis and reduced gravity flight experiments are also conducted at the NASA field centers. The International Space Station could be used as a test bed for certain technology development efforts. This paper gives a current status of technologies under development by ELS that will allow space exploration beyond low Earth orbit.

\section{INTRODUCTION}

The ELS Project's goal is to develop and mature a suite of Environmental Control and Life Support System (ECLSS) technology options for potential use on human space systems including spacecraft, planetary habitats and planetary mobility systems, which fill gaps or provide substantial improvements over the state-of-the-art in life support systems. Since space exploration missions are so challenging, mass, power, and volume must be reduced from Space Shuttle and Space Station technologies. Systems engineering analysis optimizes the overall architecture by considering all interfaces with the life support system and potential for reduction or reuse of resources. For long duration missions, technologies which aid in the closure of the atmosphere and water loops with increased reliability are essential as well as techniques to minimize or deal with waste.

NASA's spacecraft from Project Mercury, Gemini, Apollo and the Shuttle all primarily used a non-regenerable Atmosphere Revitalization System (ARS) and Water Systems. ARS was based on granular lithium hydroxide (LiOH) canisters to remove carbon dioxide $\left(\mathrm{CO}_{2}\right)$ for missions ranging from hours to weeks. $\mathrm{LiOH}$ is a good solution for short missions, but unfavorable for longer missions due to the weight of having to bring more canisters the longer the mission. With the development of Skylab, which had a mission life of months, NASA invested in a regenerable system to remove carbon dioxide based on molecular sieves, regenerated by vacuum swing and/or thermal swing. The Space Shuttle later demonstrated a regenerable amine based system, regenerated via a vacuum swing process, for carbon dioxide and partial humidity control. This was demonstrated for the Extended Duration Orbiter (EDO), which was designed for missions up to 30 days. The 
International Space Station (ISS) program, with its multiyear mission life, utilizes molecular sieves similar to Skylab. The Orion crew exploration vehicle project is currently developing an improved regenerable amine based system, regenerated via vacuum swing.

Spacecraft water has traditionally been provided by nonrecycling water systems. Water was brought up in tanks or taken as a byproduct from the fuel cells as on Shuttle and no recycling was designed into the system. Wastewater was simply dumped overboard or stored in wastewater tanks. The ISS just recently installed and is now operating the Urine Processor Assembly which recycles the urine from crewmembers aboard. The ISS also has a system for collecting and recycling water vapor from the air. This is a big advancement, but is still not a complete closed loop system. Hygiene activities loose some water into the trash and a brine wastewater is still discarded. Future systems such as a sink, shower, and laundry may be needed for long duration missions, producing additional wastewater streams.

Full closure of the atmosphere and water loops is essential to long duration exploration missions beyond low Earth orbit due to the high costs of bring all the required supplies from Earth. The new challenge of the Exploration Life Support Project is to develop a common regenerable closed loop life support system.

\section{EXPLORATION LIFE SUPPORT (ELS) PROJECT ORGANIZATION - PROJECT MANAGEMENT AND CROSS-CUTTING ELEMENTS}

The ELS Project is organized into multiple elements including a project management office. The project office is responsible for project implementation, following mandatory technology development requirements [11] and is responsible to the sponsoring program, ETDP [5]. The Work Breakdown Structure (WBS) for ELS is consistent with NPR 7120.8 [11] and is tailored toward the unique needs for spacecraft ECLSS and habitation systems (Table 2).

SYSTEMS ANALYSIS - The ELS project uses systems analysis to guide investments in technology development and evolution of life support system architectures. The Systems Integration, Modeling and Analysis (SIMA) Element of ELS fulfills this responsibility and has developed various analytical tools and resources. SIMA helps determine the equivalent system mass (ESM) of competing technologies for exploration missions as well as doing more detailed performance analysis. ESM is an analysis method developed by SIMA, which combines the launch mass of hardware and consumables with mass penalties for volume, power, heat rejection and crew time requirements into a single equivalent system mass [12]. SIMA uses the Advanced
Life Support Sizing Analysis Tool (ALSSAT) to facilitate trade studies using ESM.

Many assumptions must still be made in order to carry out meaningful analyses. Therefore, SIMA has developed and maintains various products to document mission details, analysis methods and necessary assumptions $[13,14,15]$. Within this framework, more meaningful engineering trade-off studies, architecture assessments and parametric analyses can be conducted. An example of a recent ELS study completed by SIMA is the "Bosch Carbon Dioxide Reduction System Model" [17],

Systems analyses such as these lead to findings concerning optimization of life support systems for exploration missions. For example:

- Atmosphere, water and food systems understandably require significant launch mass from Earth to support humans beyond low Earth orbit, but this amount can be cut in half by using advanced technologies under development by ELS compared to state-of-the-art [16].

- Water based laundry systems trade well for extended missions when a brine processor is used [18].

In addition to creating original models and studies, SIMA analyzes test data produced by other elements of ELS. SIMA has been heavily involved with comparison tests of water distillation technologies [21]. SIMA assists the functional elements in calculating the latest values for the element Key Performance Parameters (KPP). SIMA also assists in the calculation of Technology Readiness Levels (TRL) for hardware in the ELS portfolio.

VALIDATION AND TESTING - Through the process of technology development and maturation, component or breadboard validation is performed in laboratory environments and then moves to testing in relevant environments. This second cross cutting element provides this later function and is composed of two subelements, Flight Experiments and Integrated Testing.

Flight Experiments - The Flight Experiments technical element manages testing of technologies under hypogravity and microgravity conditions in order to complement the activities conducted in ground laboratories and ground test bed facilities. Process technologies under development by ELS will be assessed for gravity sensitivity and tested in the appropriate relevant environment to assure that the hardware performs as designed.

The Flight Experiment element technical approach is to schedule up to two flight campaigns for each fiscal year using commercial or government-owned reduced gravity 
Table 2. ELS Project work breakdown structure with example technology development tasks from within the ELS portfolio.

\begin{tabular}{|c|c|}
\hline WBS Title & Technologies $^{* *}$ \\
\hline \multicolumn{2}{|l|}{01 Project Management } \\
\hline \multicolumn{2}{|l|}{$\begin{array}{l}.02 \text { Systems Integration, Modeling, and } \\
\text { Analysis (SIMA) }\end{array}$} \\
\hline $\begin{array}{l}-01 \text { Systems } \\
\text { Engineering }\end{array}$ & TLR \& KPP calculations $\dagger$ \\
\hline -02 Systems Analysis \& Simulations & ALSSAT + \\
\hline-03 Technology Analysis and Simulations & $\dagger$ \\
\hline -04 Reference Documents & $\begin{array}{l}\text { BVAD, Reference Missions Document, } \\
\text { Requirements Document } \dagger\end{array}$ \\
\hline-05 Test Analysis & $\dagger$ \\
\hline -06 Online Project Information System & $t$ \\
\hline \multicolumn{2}{|l|}{.04 Technology Development } \\
\hline \multicolumn{2}{|l|}{.04.01 Air Revitalization Systems (ARS) } \\
\hline $\begin{array}{l}\text {-01 Carbon Dioxide Partial Pressure } \\
\text { Control }\end{array}$ & CAMRAS, SBAR, LPCOR \\
\hline-02 Control Trace VOC Concentrations & VOC Sorbents and catalysts, ESS, ATCC \\
\hline -03 Particulate Matter Removal & Atmospheric dust removal, vacuum cleaner \\
\hline -04 Resource Recovery and Recycling & $\begin{array}{l}\text { Sabatier, Bosch, methane pyrolysis, SOE, } \\
\text { TSAC, NexGenARS, ESS }\end{array}$ \\
\hline -05 Atmospheric Gas Storage and Supply & $\begin{array}{l}\text { High pressure oxygen (temperature and } \\
\text { pressure swing bed, mechanical compression, } \\
\text { electrolysis), Subcritical LOX Storage, ISRU } \\
\text { integration }\end{array}$ \\
\hline -06 Supporting Infrastructure & Quiet fan development \\
\hline \multicolumn{2}{|l|}{.04.02 Water Recovery Systems (WRS) } \\
\hline $\begin{array}{l}-01 \text { Wastewater Pretreatment and } \\
\text { Storage Systems }\end{array}$ & $\begin{array}{l}\text { Alternative urine pretreatment, cleansers, } \\
\text { detergents and personal care products }\end{array}$ \\
\hline $\begin{array}{l}\text {-02 Potable Water Disinfection and } \\
\text { Storage Systems }\end{array}$ & $\begin{array}{l}\text { Microbial control alternatives and delivery } \\
\text { systems }\end{array}$ \\
\hline $\begin{array}{l}-03 \text { Primary and Secondary Water } \\
\text { Processing Systems }\end{array}$ & $\begin{array}{l}\text { Membrane system (DOC), Rotary Distillation } \\
\text { Systems (CDS, VCD, WFRD), gravity } \\
\text { dependent water processor, bioreactors }\end{array}$ \\
\hline -04 Improved Post-processing Systems & Thermal, vapor phase and photo- catalysis \\
\hline -05 Water Recovery from Brine Systems & $\begin{array}{l}\text { Several candidate technologies are under } \\
\text { evaluation }\end{array}$ \\
\hline \multicolumn{2}{|l|}{.04 .03 Waste Management Systems (WMS) } \\
\hline $\begin{array}{l}\text {-01 Human Metabolic Waste } \\
\text { Management }\end{array}$ & Flexible Membrane Commode \\
\hline-02 Volume Reduction of Waste & Compaction, Heat Melt Compactor \\
\hline -03 Resource Recovery and Drying & Waste drying, Heat Melt Compactor \\
\hline-04 Waste Mineralization & Pyrolysis, Incineration \\
\hline -05 Waste Stabilization and Storage & $\begin{array}{l}\text { Waste drying, Heat Melt Compactor, VOC } \\
\text { characterization }\end{array}$ \\
\hline \multicolumn{2}{|l|}{.04.04 Habitation Engineering } \\
\hline $\begin{array}{l}\text {-01 Hygiene and Housekeeping } \\
\text { Technologies }\end{array}$ & Vacuum cleaner, Waste collection \\
\hline-02 Interior Clothing Systems & Advanced laundry, Advanced clothing \\
\hline -03 Crew Accommodation Technologies & Cabin Solid State Lighting \\
\hline \multicolumn{2}{|l|}{05 Validation \& Testing } \\
\hline -01 Flight Experiments & $\begin{array}{l}\text { Reduced Gravity Research Aircraft, Spacecraft } \\
\text { Flight Experiments } \dagger\end{array}$ \\
\hline -02 Integrated Testing & Test beds, Analogs $†$ \\
\hline
\end{tabular}

** Acronyms defined in Appendix. Technologies listed are currently within the ELS portfolio or have historically had funding (italics) but with future funding subject to decision points. Not all technologies are shown, including SBIRs.

† SIMA and Validation \& Testing, by their cross-cutting nature, support all needs and technologies. 
aircraft. The flights provide the opportunity for experimenters to perform tests at various levels of gravity allowing for evaluations of hardware components early in the technology development sequence. Flight experiments on the ISS and other orbital or sub-orbital platforms may be considered if necessary for research or technology validation and if sufficient resources are available.

Integrated Testing - Integrated testing, in which candidate technologies are evaluated at subsystem or systems levels while interfacing with other life support hardware and challenged by real metabolic loads, is a necessary component of any technology development activity to advance a technology's maturity level. Integrated testing allows for demonstration of technology-to-technology interface compatibility and end-to-end functionality, including operability of life support hardware and software. Integrated testing is also useful in identifying weaknesses in technologies, allowing for more efficient focusing of future technology development resources. In some cases comparison tests are conducted to obtain data to assist in the down selection of competing technologies, such that the hardware with the best characteristics are chosen for further technology advancement.

Technologies are first evaluated in a laboratory setting using component or breadboard level hardware to demonstrate basic functionality and performance. Technology maturation is achieved as higher fidelity hardware is evaluated in relevant environments. Ultimately a higher fidelity system/component, such as a brassboard or prototype, that adequately addresses scaling issues, is operated in a relevant environment to demonstrate operations under critical environmental conditions.

Future integrated tests are planned to test the closure of the ARS loop and WRS loop. Once system level hardware has been tested, integration of element systems will be tested together to ensure loop closure is achievable with habitation interfaces and incorporating waste systems. An important part of this is testing with real humans in the loop. The goal is to have a full systems level test validating all the interfaces required for a closed loop life support system.

\section{TECHNOLOGY PORTFOLIO - FUNCTIONAL ELEMENTS}

The ELS portfolio is evaluated yearly and documented in the ELS Project Plan $[3,22]$. The Work Breakdown Structure (WBS) for ELS is given in Table 2, with associated technology development tasks.

ATMOSPHERE REVITALIZATION SYSTEM (ARS) One of the ARS element objectives is closure of the ARS loop, including advanced carbon dioxide removal, carbon dioxide reduction, oxygen generation and trace contaminant control. Technologies and interfaces in support of Extravehicular Activity (EVA) recharge, pressurized rovers and In Situ Resource Utilization (ISRU) will be investigated. Figure 1 shows the additional functions required to close the ARS loop.

The first step is to remove the carbon dioxide and moisture from the atmosphere without binding it up in a non-reversible chemical reaction, which occurs with $\mathrm{LiOH}$ canisters, and without dumping it overboard via a vacuum desorption system. One such technology is the Low-Power $\mathrm{CO}_{2}$ Removal (LPCOR) system. The system incorporates a membrane dryer instead of desiccant beds, which are used in the four bed molecular sieve $\mathrm{CO}_{2}$ removal technology on ISS. The membrane requires less energy for regeneration improving the efficiency of the system. The LPCOR also has a two-stage $\mathrm{CO}_{2}$ removal and compression system that was designed this year. Fabrication is currently underway and is expected to be completed by the end of the year. The first stage removes the $\mathrm{CO}_{2}$, partially compresses, and delivers it to the second stage. The second stage compresses the $\mathrm{CO}_{2}$ to the level required by a $\mathrm{CO}_{2}$ reduction unit. The $\mathrm{CO}_{2}$-free air is returned to the atmosphere after picking up moisture that was removed from the membrane dryer. Also under development is an Engineered Structured Sorbent (ESS) system. This system consists of a low power bulk desiccant module that removes water without thermal regeneration, followed by a string of Microlith $\AA$ based adsorber modules container zeolite sorbent coated onto an expanded metal substrate. The Microlith $®$ combines dense sorbent packing with the ability for fast and thorough regeneration, maximizing sorbent capacity and thermal efficiency. The ESS system is compatible for integration with loop closure technologies for $\mathrm{CO}_{2}$ reduction and compression.

A $\mathrm{CO}_{2}$ compression system under development is the Temperature Swing Adsorption Compressor (TSAC) which performs as a link between $\mathrm{CO}_{2}$ removal and reduction units by performing $\mathrm{CO}_{2}$ recovery, purification, storage, compression and delivery functions. TSAC utilizes an adiabatic thermal cycling process that involves the adsorption and regeneration of $\mathrm{CO}_{2}$ using an adsorbent. It has demonstrated the ability to deliver compressed $\mathrm{CO} 2$ at a controlled rate, as per demand, at constant pressure.

It is important to remove certain chemicals that are harmful to humans and that may have a negative performance impact on ARS adsorbents. Trace contaminant control systems accomplish this currently on Shuttle and ISS. Subscale evaluations of commercial adsorbents and catalysts for trace contaminant control are being conducted to try to achieve improved performance, reliability and reduced complexity. The focus is on trace levels of $\mathrm{NH}_{3}$ and $\mathrm{CH}_{2} \mathrm{O}$. Results for $\mathrm{NH}_{3}$ analysis so far this year include materials from seven different companies. Once a promising material is 
identified via small-scale testing, the design of a large scale unit will be pursued and then tested. Evaluations are also being conducted on existing amines and zeolites for non-methane volatile organic compounds found in spacecraft cabin atmospheres. Data will be used for model validation, conducting trade studies of adsorbents, sizing of trace contaminant control beds and for optimization of regeneration cycles. Advanced Trace Contaminant Control (ATCC) systems are being investigated including photo catalytic oxidation, thermal catalytic oxidation and regenerable adsorbent process technologies.

Advanced particulate matter filters are being researched that would be regenerable, more efficient at handling ultra-fines, and extend the current life over the state-ofthe-art. A vacuum cleaner is also in development that would be able to clean particulate matter, including lunar dust, from surfaces as well as the atmosphere in an airlock.

Several technologies, including Microwave Plasma Methane Pyrolysis post-processing reactor for Sabatier based processes, Bosch reactor systems, and Solid Oxide Electrolysis, are being developed for the next step in a closed loop ARS - carbon dioxide reduction. The best technology option will be down-selected in FY11 for further development to achieve a high degree of function with moderate fit and form in a closed loop architecture with emphasis on interactions between oxygen generation, trace contaminant removal, $\mathrm{CO}_{2}$ removal, $\mathrm{CO}_{2}$ transfer and $\mathrm{CO}_{2}$ reduction.

A horizontal-Bosch reactor system was refurbished this year allowing the development of alternative operational modes for improved efficiency. The design and fabrication of a Bosch Catalyst Test Stand facilitated the identification of alternate Bosch catalyst materials and supports for improved efficiency and regeneration.

A Sabatier-Microwave Plasma Methane Pyrolysis integration rig was designed and fabricated this year which will allow further integrated testing of this closed loop technology. Stand alone testing was performed with each technology to improve function prior to integration.

Additional regenerable methane pyrolysis catalysts have been identified and will be tested in the future. The ARS element investigated what technologies are being used in industry and will conduct a technical interchange meeting this year to incorporate industry knowledge and expertise.

The Next Generation Atmosphere Revitalization System (NexGenARS) is a consolidated design of the $\mathrm{CO}_{2}$ removal, recovery and regenerable trace contaminant control subsystems with flexible integration options to $\mathrm{CO}_{2}$ reduction and water recovery systems. The focus will be on designing solutions to issues related to flow dynamics and mass and heat transfer rates and optimizing integration between system components. Any ARS requires air flow to function so an advanced quiet, efficient fan is being designed applying principles from quieting large aircraft engines. The next step will be to build the quiet fan and conduct tests to ensure it meets the requirements of the NexGenARS.

Any closed loop ARS will require oxygen generation, most likely from water. Additionally, pressurization of the oxygen will be required to enable storage. For example, the EVA system requires ELS to recharge their backpack oxygen tanks to 3000 psia. There are currently several technologies being studied to provide high pressure oxygen, including Temperature Swing Adsorption Compressor, Mechanical Compressor, liquid oxygen Vaporizer and High Pressure Electrolysis. Supporting technologies are also under study, such as oxygen dryers (to keep moisture out of compressors) and Pressure Swing Adsorption systems (to remove oxygen from the air).

The temperature swing system would compress liquid oxygen propellant tank boil-off via a low temperature high pressure sorbent. A cryogenic, high pressure adsorption apparatus is being built to test potential sorbents. A three-stage mechanical compressor is being tested to evaluate performance and lifetime. An electrolysis cell stack test article was developed and a flammability test was conducted to evaluate safety issues. A pressure swing adsorption system was tested, showing capability of producing greater than $99 \%$ pure oxygen from spacecraft cabin air. Besides the pressurization technologies, some design concepts for storage of cryogenic liquid oxygen (LOX) have been studied for long term storage. This work is being coordinated with other ETDP projects which have plans to use LOX.

WATER RECOVERY SYSTEMS (WRS) - The WRS element is primarily focused on development of closedloop water recovery systems, as shown in Figure 2, where recovery and production of potable water from wastewater with high levels of closure is necessary for extended duration missions beyond low Earth orbit. The Shuttle does not recycle any water, nor does the Orion crew exploration vehicle plan to. The ISS recycles urine and humidity condensate, but it does not close the WRS loop entirely as the brine waste water and wet trash is disposed. Initial ELS emphasis is on development and evaluation of physicochemical systems that can recover greater than $90 \%$ of wastewater to potable water quality. Technologies for further recovery of water from waste brines are being investigated to increase the level of closure. There is also potential for bioregenerative systems to become more viable for longer duration missions beyond low Earth orbit.

Primary processors in development fall into two main categories: Membrane Systems and Rotary Distillation 
Systems. One membrane technology under development is the Direct Osmotic Concentration (DOC) system. The DOC is a highly integrated membrane treatment process that incorporates Forward Osmosis (FO) membrane evaporation process, Reverse Osmosis (RO) desalination, and a catalytic oxidation post treatment. The system is designed to accept separated hygiene, urine and humidity condensate wastewater streams and produce a potable quality product.

There are three rotary distillation processors in development and are currently completing a comparison test to support a down selection process for future distillation technology development. The three distillers are the Vapor Compression Distillation (VCD) system, Wiped-Film Rotating Disk (WFRD) system, and Cascade Distillation Subsystem (CDS). The VCD uses pumps to discharge wastewater to the inner surface of a low pressure rotating evaporator drum and the resulting vapor is compressed and condensed on the outer surface of the drum generating heat for distillation. Noncondensable gases are vented to the atmosphere. The CDS uses vacuum distillation at low pressure in a multistage rotary processor. Centrifugal forces transport the fluids in the processor, eliminating pumps. Each stage is maintained at successively lower operating pressure allowing heat of vaporization to be recovered. The WFRD vapor compression distillation differs from conventional systems in that it uses a highly efficient wiped-film rotating disk evaporative condenser. Wastewater is fed along the length of stationary wipers on the outside surface of rotating disks so it is spread uniformly and in a very thin film allowing for evaporation. Each of these systems produces a fairly clean distillate, but all still require a post-processor for final polishing before the water is potable. The ELS project is also studying a simplified water processor that may take advantage of partial gravity and solar energy and be able to recover water from brine as well.

Water recovery from brine allows the water loop to reach nearly complete closure. Brine is the wastewater remaining from the primary processor. There are several technologies being researched and developed to recover the remaining water in the brine as standalone systems or by systems that recover water from brine and wastes simultaneously. These technologies include spray drying, microwave drying, infrared drying, heat melt compaction, and others, which are still being investigated. The heat melt compactor recovers water and stabilizes waste into sterile, compact, plastic encapsulated disks assuming the waste stream has a sufficient amount of plastic to start with. Pneumatic pistons compress the waste and electric heaters heat the waste, melting the plastic and vaporizing the water, which is then condensed and recovered. The technologies that dry waste, stabilize it, lower odor, reduce the potential for microbial growth, and allow it to occupy smaller storage volume. Technologies under development will be designed to minimize off-gassing of contaminants and to avoid significant impact to the trace contaminant control system of the ARS by using low temperature removal of the water, by heating the water while minimizing the heating of solids, and by catalytically destroying contaminants at the source.

Post-processing is required for the water coming out of the primary processor and brine systems. An advanced thermal catalyst is under development to operate at ambient pressure to reduce mass and power and improve reliability. Four potential catalysts have been evaluated in performance and life tests. The feasibility of using emerging solid-state lighting technologies for photolytic and photo-catalytic disinfection is being studied using low-power ultraviolet Light Emitting Diodes (LEDs) or fiber optics for transmission of natural ultraviolet radiation from the Sun. Proof of concept testing of deep UV-c and UV-A LEDs for water treatment and viral disinfection using advanced oxidation processes in the presence of titanium dioxide and nanosilver particles have been completed. Further testing is required to make a viable LED system. Vapor phase catalysis has potential for increased efficiency compared to aqueous phase systems due to improved mass transfer in the vapor phase. The task is currently focusing on evaluating alternative vapor phase catalysts that have improved reliability.

To maintain the stability of urine until it is processed in the primary processor, a pretreatment is added. If the urine is not pretreated urea hydrolysis occurs causing an increase in $\mathrm{pH}$ and formation of alkaline precipitates which may be harmful for primary processors. One of the current pretreatments is toxic and could form toxic off-gases associated with chemical oxidation. The goal is to develop a less toxic option along with an effective delivery system that minimizes crew time. In a related task, products such as crew hygiene products, cabin cleaning solutions, and laundry detergents that may end up in the wastewater stream are being researched to identify any potential system impacts. To maintain the stability of stored water, a biocide is added to maintain a low microbial load. Alternative biocide formulations and delivery systems are under development. 


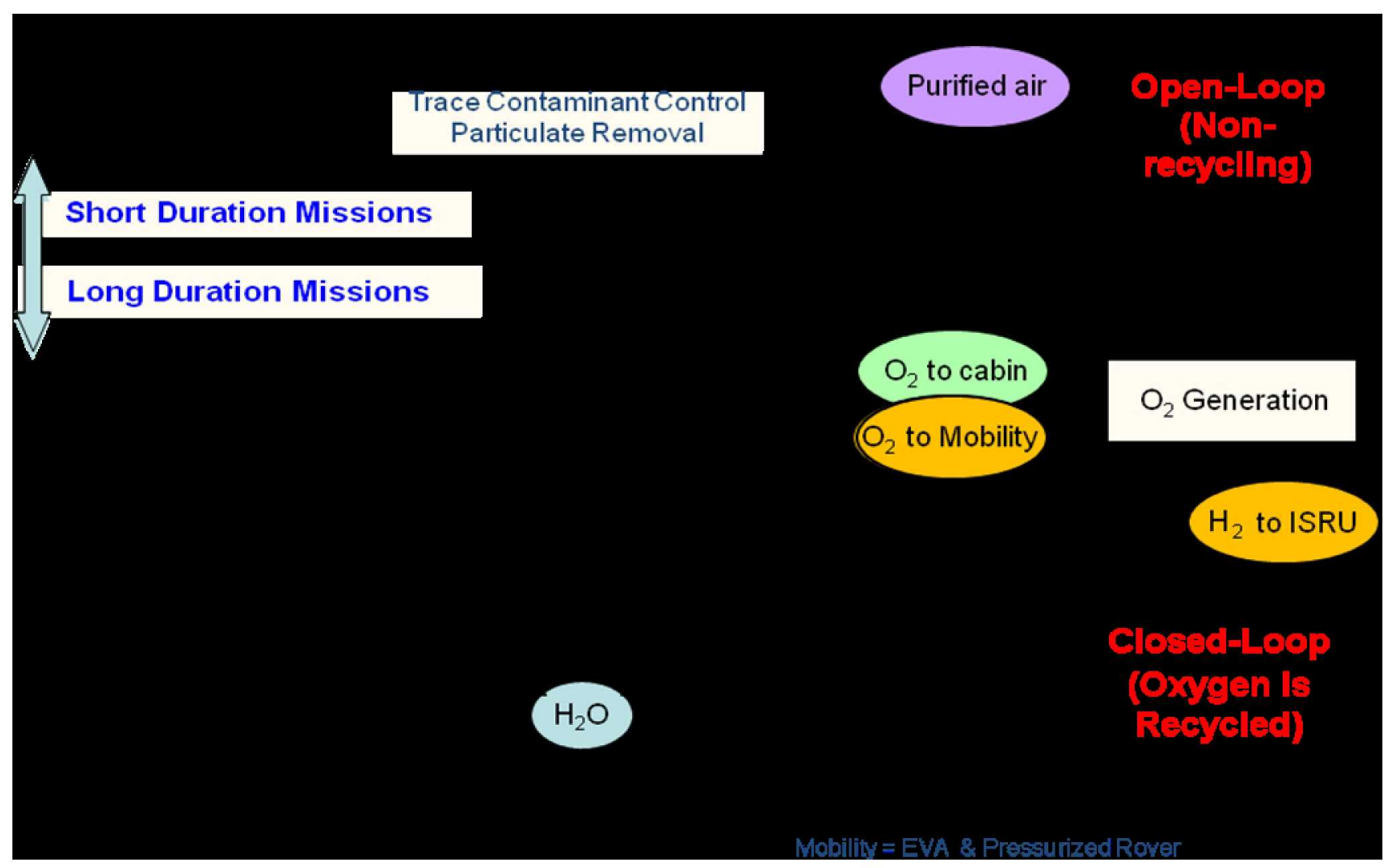

Figure 1. Open to Closed-Loop Atmosphere Revitalization System (ARS) 

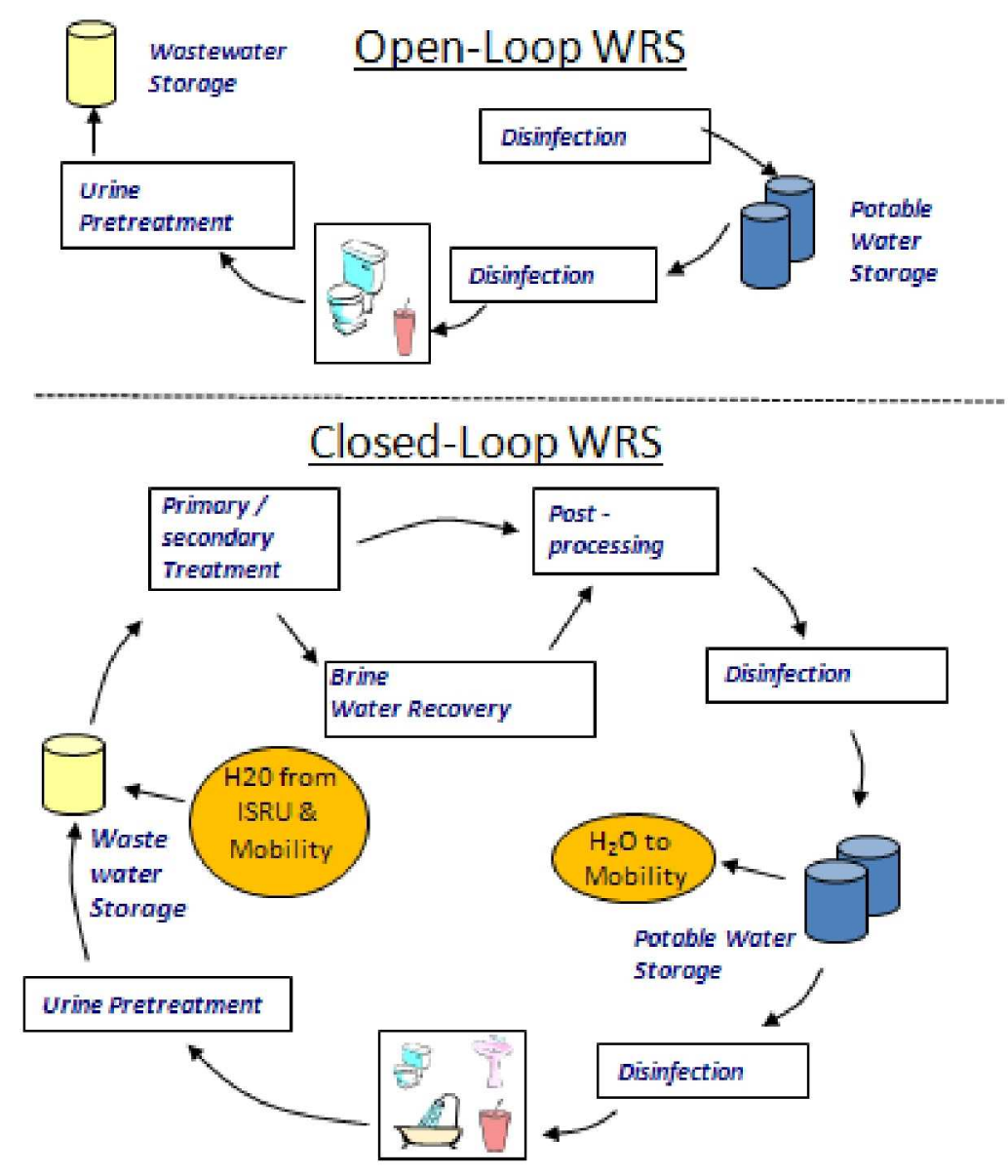

Figure 2. Open \& Closed Loop Water Recovery Systems (WRS)

WASTE MANAGEMENT SYSTEM (WMS) - The WMS element is focused on the development of waste management technologies to recover resources, increase crew safety and performance, and protect planetary surfaces while decreasing mission cost. Technology gaps to be addressed are stabilization and odor control, water recovery, waste/trash volume reduction, and disposal. The Heat Melt Compactor, described above, is a promising technology for accomplishing these challenges. Pyrolysis technology is a more complete thermal waste processing system that both stabilizes the waste and provides the potential to recover methane fuel as well as water. Waste is heated in the absence of oxygen until a thermally induced chemical decomposition takes place that converts the waste to vapors, liquids, and a small amount of residual char. In some technologies complex product streams include tars and toxic gases which cannot be vented into habitable environments. Thus clean up of these products is important in ELS development work so that the resulting gases can either be safely vented to the cabin or overboard. On Mars venting becomes more of an issue due to planetary protection concerns.
HABITATION ENGINEERING - Habitation Engineering is a distinct technology area directly applicable to human mission success. It provides crew interfaces to life support equipment and improves crew function, comfort, and quality of life to enhance crew productivity. Capabilities have historically been designed for Low Earth Orbit (LEO) missions with frequent resupply, and thus may not be sufficiently optimized for reliability, mass, volume, or autonomy which are critical design drivers for exploration missions beyond low Earth orbit. Development of systems for use in partial gravity, low atmospheric pressure and elevated oxygen concentrations will be a challenge. The ELS project has already begun development of a vacuum cleaner and is making plans for additional crew accommodations hardware such as a laundry system to allow reuse of clothing. Early consideration of crew required functions such as this are important because of their strong interaction with the ARS, WRS and WMS.

\section{CONCLUSION}

The Exploration Life Support technology development project is responsive to changes in architectures, 
requirements and organizational relationships as NASA's implementation of U.S. space exploration matures and as exploration beyond low Earth orbit becomes better defined. The ELS project has a well established, active group of technologists throughout the agency dedicated to carrying out U.S. space exploration policy by reducing life support consumables and improving system performance and robustness through the closure of the atmosphere and water system loops.

\section{ACKNOWLEDGMENTS}

The authors wish to thank Chantel Whatley, the ELS Technical Element Leads, including Molly Anderson, James Broyan, John Fisher, Nancy Hall, Jay Perry, and Karen Pickering, and all participants within the ELS technology development community.

\section{REFERENCES}

1. National Aeronautics and Space Administration, "Exploration Systems Architecture Study", NASA, Washington, D.C., NASA-TM-2005-214062, 2006.

2. Chambliss, J., B. M. Lawson and D. J. Barta, "New Direction of NASA Exploration Life Support", SAE Paper 2006-01-2241, International Conference On Environmental Systems, July 17-20, 2006, Norfolk, Virginia, USA.

3. Barta, D.J., M.K. Ewert and J McQuillan. "Life Support System Technology Development Supporting Human Space Exploration", SAE Paper 2008-01-2185, International Conference On Environmental Systems, June 29-July 3, 2008, San Francisco, California, USA.

4. "Constellation Program Technology Insertion Strategy Document", (2007), NASA Document CxP 70079.

5. "Exploration Technology Development Program (ETDP) Research and Technology Program Plan", ETDP-0054, NASA Langley Research Center, Langley, VA, October 23, 2008.

6. Ham, L.J., "Constellation Program's Technology Development Needs", $3^{\text {rd }}$ Exploration Conference and Exhibit, Denver, CO, USA, February 26, 2008.

7. Carrasquillo, R.L., R.M. Bagdigian, M.S. Anderson and J.F. Lewis, "Life Support Requirements and Technology Challenges for NASA's Constellation Program", SAE Paper 2008-01-2018, International Conference On Environmental Systems, July 12-July 16, 2009, Savannah, Georgia, USA.

8. Anderson, M.S., "Life Support Systems for Lunar Landers", SAE 2008-01-2172, 38th International Conference on Environmental Systems, June 29July 2, San Francisco, CA.

9. Bagdigian, R. M., "Considerations Regarding the Development of an Environmental Control and Life Support System for Lunar Surface Applications", SAE Paper 2008-01-2187, International Conference
On Environmental Systems, June 29-July 3, 2008, San Francisco, California, USA.

10. Bagdigian, R. M., "Challenges with Deploying and Integrating Environmental Control and Life Support Functions in a Lunar Architecture with High Degrees of Mobility", SAE Paper 2009-01-2481, International Conference On Environmental Systems, July 12-July 16, 2009, Savannah, Georgia, USA.

11. National Aeronautics and Space Administration, "NASA Research and Technology Program and Project Management Requirements", NPR 7120.8, Washington, D.C., 2008.

12. “Advanced Life Support Equivalent System Mass Guidelines Document," NASA TM-2003-212278, Levri, J.A., Drysdale, A. E., Ewert, M.K., Fisher, J.W., Hanford, A.J., Hogan, J. A., Jones, H.W., Joshi, J.A., and Vaccari, D.A., Authors, National Aeronautics and Space Administration, Ames Research Center, Moffett Field, CA.

13. Duffield, B.E., Editor, "Exploration Life Support Baseline Values and Assumptions Document," ESCG-4470-08-TEAN-DOC-0301, Engineering and Science Contract Group, Jacobs Sverdrup, Houston, Texas, USA, 2008.

14. Duffield, B.E., "Exploration Life Support Reference Missions Document," JSC 64109, NASA Johnson Space Center, Houston, Texas, USA, 2008.

15. Perka, A.T., Editor. "Exploration Life Support Requirements Document," JSC-65527A (CTSDADV-631, rev. A), NASA Johnson Space Center, Houston, Texas, 2008.

16. Yeh, H.Y., "Exploration Life Support R\&TD Metric of the Lunar Outpost - Fiscal Year 2008 (Revision A)", ESCG-4470-08-TEAN-DOC-0411, Engineering and Science Contract Group, Jacobs Sverdrup, Houston, TX, USA, February 17, 2009.

17. Fritts, S.D., "Bosch Carbon Dioxide Reduction System Model", ESCG-4470-08-TEAN-DOC-0282, Engineering and Science Contract Group, Jacobs Sverdrup, Houston, TX, USA, June 11, 2008.

18. Jeng, F., “Laundry Study for Constellation”, ESCG4470-08-TEAN-DOC-0281, Engineering and Science Contract Group, Jacobs Sverdrup, Houston, TX, USA, August 18, 2008.

19. Lange, K.E., "SPR ECLSS Sizing Analysis: Carbon Dioxide and Humidity Control" presentation, Engineering and Science Contract Group, January 14, 2009.

20. Allada, R., "Post-test Modeling and Analysis of Phase I CAMRAS/Constellation Suit Integrated Test", ESCG-4470-08-TEAN-DOC-0310, Engineering and Science Contract Group, Jacobs Sverdrup, Houston, TX, USA, July 31, 2008.

21. Allada, R., L. A. Crenwelge, "Water Recovery Technology Development", ESCG-4470-08-TEANDOC-0383

22. "Technology Development Plan, Exploration Life Support (ELS)", Document Number JSC-65690A, 
NASA Johnson Space Center, Houston, TX, USA, October 21, 2008.

\section{CONTACT}

Daniel J. Barta, ELS Project Manager

NASA Johnson Space Center

Mail Code EC1, Houston, TX, 77058

daniel.j.barta@nasa.gov

http://els.jsc.nasa.gov

\section{ACRONYMS}

ALSSAT: Advanced Life Support Sizing Analysis Tool

ARC: Ames Research Center

ARS: Atmosphere Revitalization Systems

ATTCS: Advanced Trace Contaminant Control System BVAD: Baseline Values and Assumptions Document

$\mathrm{CO}_{2}$ : Carbon Dioxide

CAMRAS: Carbon-Dioxide and Moisture Removal Amine Swing-Bed

CCSIT: Carbon Dioxide and Moisture Removal Amine Swing bed (CAMRAS) / Constellation Suit Integrated Test

CDR: Critical Design Review

CDS: Cascade Distillation Subsystem

CEV: Crew Exploration Vehicle

CFR: Carbon Formation Reactor

COTS: Commercial Off The Shelf

CR: Contractor Report

CTSD: Crew and Thermal Systems Division

CxP: Constellation Program

DOC: Direct Osmotic Concentration

ECLS: Environmental Control and Life Support

ECLSS: Environmental Control and Life Support

System

ELS: Exploration Life Support

ESAS: Exploration Systems Architecture Study

ESM: Equivalent System Mass

ESMD: Exploration Systems Mission Directorate

ESS: Engineered Structured Sorbents

ETDP: Exploration Technology Development Program

EVA: Extra-Vehicular Activity

EWRS: Exploration Water Recovery System

FY: Fiscal Year

GRC: Glenn Research Center
$\mathrm{H}_{\mathbf{2}}$ : Hydrogen

HE: Habitation Engineering

HQ: Headquarters

IC: Initial Capability

ISRU: In Situ Resource Utilization

JSC: Johnson Space Center

KDP: Key Decision Point

KPP: Key Performance Parameter

KSC: Kennedy Space Center

LaRC: Langley Research Center

LED: Light Emitting Diode

LEO: Low Earth Orbit

LOCR: Lunar Operations Concept Review

LOX: Liquid Oxygen

LPCOR: Low Power $\mathrm{CO}_{2}$ Removal

LSS: Lunar Surface Systems

LT: Lunar Transport

LWCWT: Light Weight Contingency Water Treatment

MSFC: Marshall Space Flight Center

NASA: National Aeronautics and Space Administration

NGARS: Next Generation ARS

NP: NASA Publication

NPR: NASA Procedural Requirements

OD: Osmotic Distillation

P/C: Physicochemical

PDR: Preliminary Design Review

R\&TD: Research and Technology Development

SBAR: Sorbent-Based Atmosphere Revitalization

SDR: Systems Definition Review

SOE: Solid Oxide Electrolysis

SPR: Small Pressurized Rover

SRR: Systems Requirements Review

SIMA: Systems Integration, Modeling, and Analysis

TM: Technical Memorandum

TPP: Technology Prioritization Panel

TRL: Technology Readiness Level

TSAC: Temperature Swing Adsorption Compressor

U.S.: United States

V\&T: Validation and Testing

VCD: Vapor Compression Distillation

VOC: Volatile Organic Carbon

VPCAR: Vapor Phase Catalytic Ammonia Removal

WBS: Work Breakdown Structure

WFRD: Wiped-Film Rotating Disk

WMS: Waste Management System

WRS: Water Recovery System 